\title{
Effects of acute exposure to static magnetic field on ionic composition of rat spinal cord
}

\author{
Elferchichi Miryam, Lahbib Aida, Missaoui Samira, Sakly Mohsen and Abdelmelek Hafedh
}

Laboratoire de Physiologie Integrée, Faculté des Sciences de Bizerte, Jarzouna, Tunisia

\begin{abstract}
The purpose of this study is to evaluate the effect of static magnetic fields (SMF) on ionic composition of rat spinal cord. Male Wistar rats were daily exposed to SMF of $128 \mathrm{mT}$, for $1 \mathrm{~h} /$ day during five consecutive days. Spinal cord samples were extracted, weighed and mixed in bidstilled water in order to be analyzed by inductively coupled plasma (ICP). Plasma ionic composition was also made. Acute exposure to SMF increased significantly the calcium $(+68 \%, p<0.05)$ and iron $(+35 \%, p<0.05)$ contents of rat spinal cord, whereas magnesium and copper levels remained unchanged. In plasma, SMF treatment failed to alter calcium concentration but decreased iron level $(-17 \%, p<0.05)$.

These data indicate that SMF acute exposure can induce alterations of ionic composition in the rat spinal cord and the plasma electrolytes balance.
\end{abstract}

Key words: Static magnetic field - Ionic composition — Spinal cord - Plasma - Rats

\section{Introduction}

Numerous sources of static magnetic fields (SMF) exist in nature, and in the occupational and residential environments. The influence of SMF on biological systems has been a topic of considerable interest for many years because of the increase of strong SMF $(>1 \mathrm{~T})$ generated by superconducting magnets (Ichioka et al. 1998). One reason why it is extremely important to deeply understand the true mode of action of SMF on living organisms, is the need to protect human health in consideration of the probable future introduction of new technologies such as magnetically levitated trains and the therapeutical use of SMF (e.g. magnetic resonance imaging (MRI) coupling of magnetic field exposure with chemotherapy). In fact, the ability of these fields to produce effects on living organisms is still a matter of debate. Nevertheless, there is substantial evidence indicating that SMF are capable of influencing a number of biological systems, particularly those whose function is closely linked to the properties of membrane channels. Most of the reported SMF effects may be explained on the basis of alterations in membrane calcium ion flux (Rosen 2003). Studies have found effects on calcium signalling (Fanelli et al. 1999), apoptosis (Fanelli et al. 1999;

Correspondence to: Miryam Elferchichi, Laboratoire de Physiologie Integrée, Faculté des Sciences de Bizerte, 7021 Jarzouna, Tunisia E-mail: Elferchichi.miryam@yahoo.fr
Buemi et al. 2001), gene expression (Lin et al. 1994), cell proliferation (Buemi et al. 2001), events involving generation of free radicals (Roy et al. 1995), and micronuclei induction (Suzuki et al. 2001). SMF exposure disrupts the mineral content in the frog sciatic nerve, especially calcium and iron (Amara et al. 2004). Furthermore, Lai and Singh (2004) showed that magnetic field exposure affects iron homeostasis in certain cells, leading to an increase in free iron in the cytoplasm and nucleus, which, in turn, leads to an increase in hydroxyl radicals via the catalytic activity of the Fenton reaction. Magnetic fields may disturb the electrolyte balance in the human placenta (Lopucki et al. 2004), change the liver and kidney concentration of copper, manganese, cobalt, and iron (Duda et al. 1991). Therefore, alteration of ionic composition in plasma or tissue following magnetic field can lead to disastrous consequences especially to the central nervous system (CNS). It is well-known that the CNS is protected by the bloodbrain barrier, a blockade of cells separating the circulating blood from elements of the CNS it acts as a filter, preventing many substances from entering brain and spinal cord. In fact, it has been reported that magnetic field exposure can alter blood-brain barrier by increasing its permeability to albumin (Finnie 2002), ions (Quock 1987) and increase the risk of Alzheimer's and Parkinson's diseases ( $\mathrm{Li}$ and Sung 2003). Burchard et al. (1999) reported that exposure to electric and magnetic fields $(60 \mathrm{~Hz}, 10 \mathrm{kV} / \mathrm{m}$, and 30 $\mu \mathrm{T})$ resulted in decreased concentrations of magnesium, 
increased level of calcium and phosphor in blood plasma, and decreased concentrations of iron and manganese in cerebrospinal fluid. Very little is known concerning the SMF influence on concentration of some trace elements, in the CNS subjected to SMF.

The aim of the present work is to experimentally investigate the effects of acute exposure to $128 \mathrm{mT}$ SMF on the ionic composition of rat plasma and spinal cord.

\section{Materails and Methods}

\section{Animals and protocol}

Animal care and experimental procedures were carried out in accordance with the Tunisian Code of Practice for the Care and Use of Animals for scientific purposes and the protocol was approved by the Ethic Committee of the University of 7 November, Tunisia.

Twelve 6-7-week-old male Wistar rats weighting 200-250 $\mathrm{g}$ at the time of experiments were housed (3/cage) in a temperature-controlled room at $25^{\circ} \mathrm{C}$ with a relative humidity of $80 \%$ and a $12: 12 \mathrm{~h}$ light-dark cycle (light on at 8 a.m.). Water and food were available ad libitum. Rats were randomly divided in two groups: rats exposed to 128 $\operatorname{mT} \operatorname{SMF}(n=6, \mathrm{SMF})$ for $1 \mathrm{~h} /$ day during five consecutive days and sham control rats ( $n=6$, sham control) placed in the electromagnet without exposure to SMF.

\section{Exposure system}

We used an electromagnet (Model EM4-HVA, Lake Shore Cryotronic. Inc., Westerville, $\mathrm{OH}$, USA) and a magnet power supply (Model 647, Lake Shore Cryotronic. Inc.) with an air gap of $11 \mathrm{~cm}$ (Figure 1). This apparatus incorporates water-cooled coils and precision yokes that assure precise cap alignment and excellent field stability and uniformity when high power is required to achieve the maximum field capability for the electromagnet. SMF intensity was measured and standardized over the total floor area of the Plexiglas cage at $128 \mathrm{mT}$. SMF uniformity in the active exposure volume was $\pm 0.2 \%$ over $1 \mathrm{~cm}^{3}$. The cage measured $20 \times 10 \times 20 \mathrm{~cm}$. The two bobbins of the Lake Shore electromagnet were separated by a $12.1 \mathrm{~cm}$. Exposed and sham control rats $(n=2$ /each time) were placed in the cage at the center of the uniform field area and exposed, or not, to $128 \mathrm{mT}$ SMF.

The SMF of exactly $128 \mathrm{mT}$ was choosen according to previous data obtained in our laboratory, which revealed that $128 \mathrm{mT}$ was the minimal intensity which can induce disruption of body temperature. Thus, we used this intensity

A

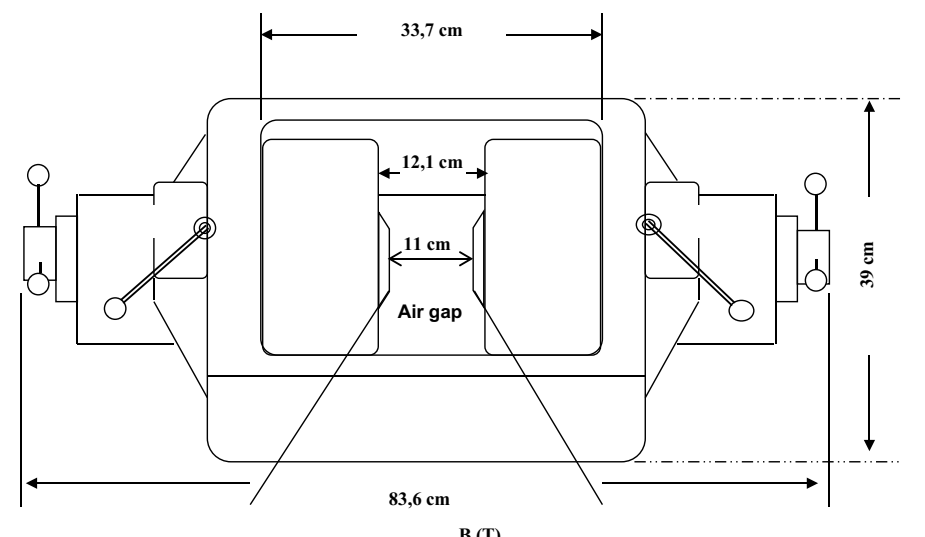

B

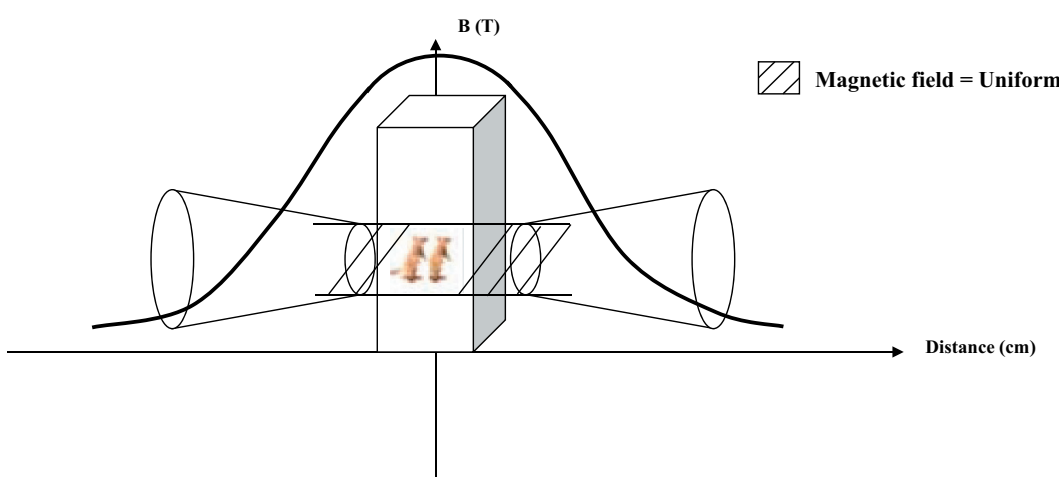

Figure 1. Electromagnet (Model EM4-HVA) dimensions (front view, A) and magnetic field propagation (B). B, magnetic induction. 
for all our research in order to explain the physiological dysfunction (Abdelmelek et al. 2000, 2001).

\section{Blood chemistry}

At the end of the fifth day of exposure, exposed and sham exposed rats were sacrificed by decapitation, just behind the ears to avoid touching the cervical part of the spinal cord. Blood was immediately collected and centrifuged and plasma aliquots were frozen and stored at $-80^{\circ} \mathrm{C}$ until use. Plasma iron was measured by using colorimetric methods according to manufacturer instructions (Biomaghreb, Réf. 20061). Plasmatic calcium was determinated by o-cresolphtaleine (Reactif Kit Modular P, Roche, Belgium).

\section{Tissue sampling}

Immediately after decapitation, animal was placed out ventral side. A midline incision that allows to exposure the vertebral column after emptying the lumbar and thoracic cavities was made, as shown in Figure 2. The entire vertebral column was carefully removed, after identification of the first cervical vertebra, count 8 cervical, 13 thoracic and 6 lumbar segments. Conventionally, the part of the column between cervical 1 and lumbar 2, which correspond to the spinal cord, was isolated.

\section{Chemical assays}

Spinal cord samples of treated and control rats were extracted, weighed and mixed in bidistelled water. Minerals were assayed simultaneously by inductively coupled plasma (ICP), an analytical technique used for the detection of trace metals in environmental samples. An ICP is a high temperature (6000-10000 K) excitation source that efficiently desolvates, vaporizes, excites, and ionises atoms. Molecular interferences are reduced with this excitation source. An ICP requires that the element, which is to be analysed, must be present in solution. The homogeneous

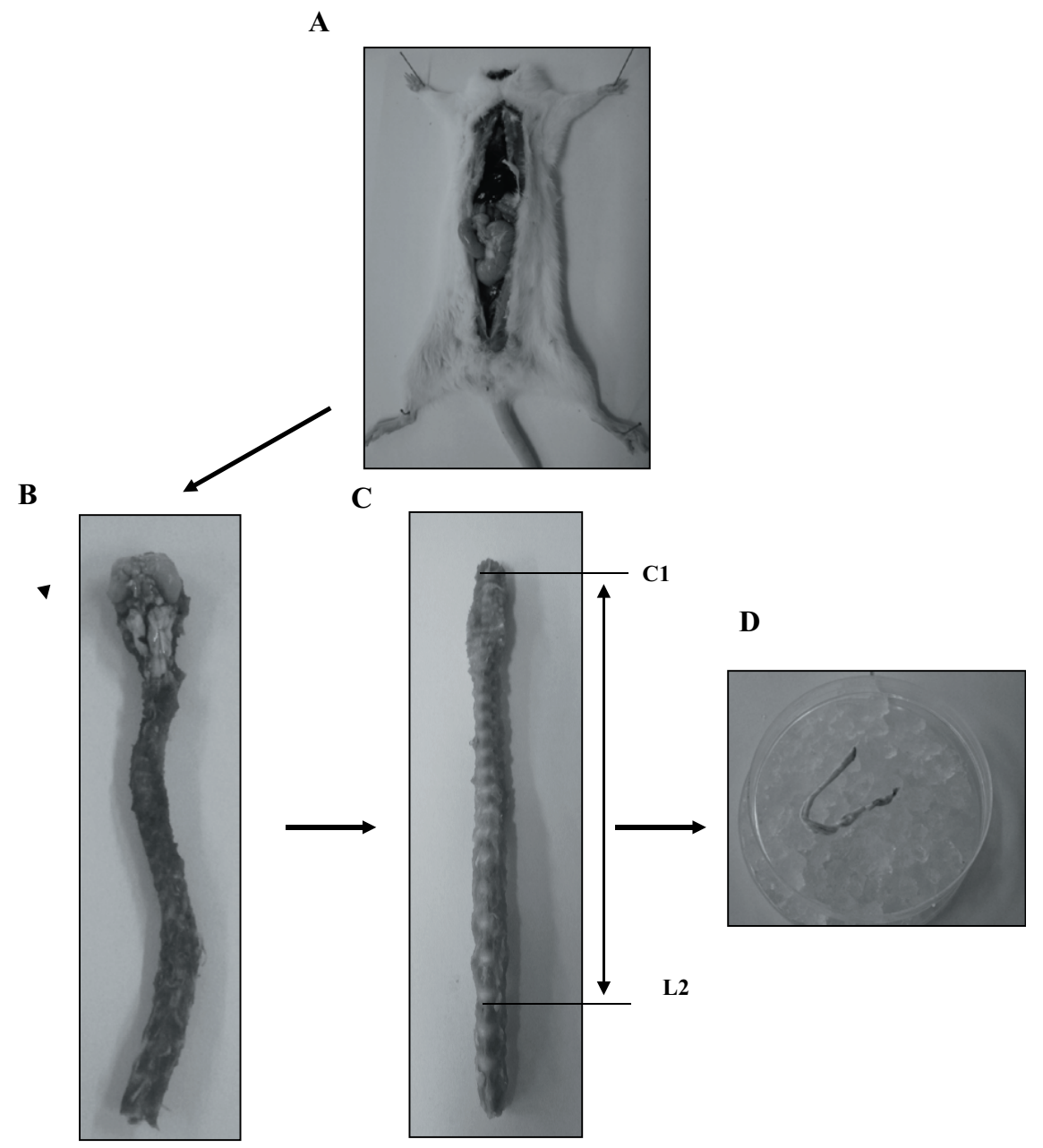

Figure 2. Description of the rat spinal cord dissection. A. The midline incision. B. Vertebral column. C. Section of vertebral column from cervical vertebra 1 (C1) to lumbar vertebra 2 (L 2). D. Isolated rat spinal cord. 


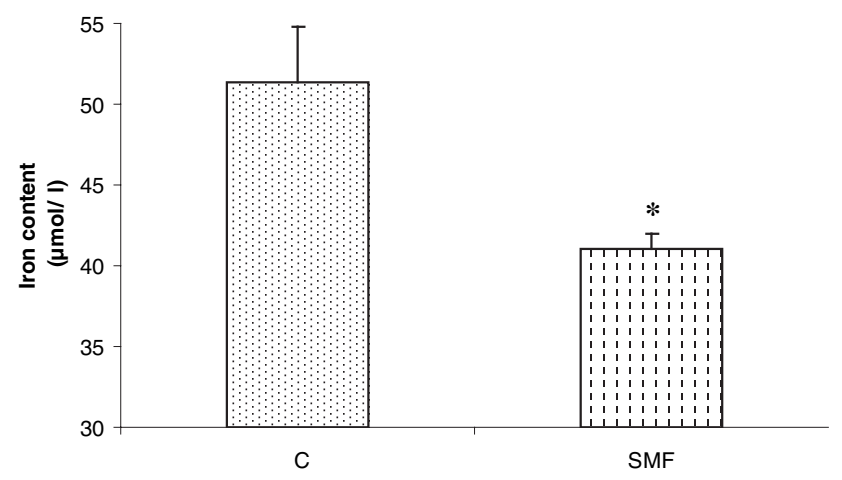

Figure 3. Effect of acute exposure to static magnetic field on plasmatic iron content. Values are means \pm SEM calculated from $n=6$ in each group. C, sham control; SMF, exposed rats; ${ }^{*} p<0.05$ vs. C.

solutions were transformed by spraying in aerosol ionized with gasified argon plasma in high temperature. An ionic detector record ionic transmission permits the measurement of ions and calculates directly after logical treatment the concentration of analyzed elements: spinal content of calcium, iron, magnesium and copper. The protocol used in this investigation was previously used in our laboratory by Amara and co-workers (Amara et al. 2004).

\section{Data presentation and statistical analysis}

Data were reported as the mean \pm SEM. Differences between means were evaluated by one-way analysis of variance (ANOVA). Statistical significance of the differences between means was assessed by Student's $t$-test. The level of significance was set at $p<0.05$.

\section{Results}

\section{Body weight and relative spinal cord weight}

SMF exposure failed to alter body weight of exposed rats compared to sham ones $(235.8 \pm 5.2 \mathrm{~g} v s .238 .0 \pm 4.9 \mathrm{~g}, p>$

Table 1. Effect of acute SMF exposure on rat body weight and relative spinal cord weight

\begin{tabular}{lcc}
\hline & Sham control & SMF \\
\hline Body weight (g) & $238.0 \pm 4.9$ & $235.8 \pm 5.2$ \\
$\begin{array}{l}\text { Relative spinal cord weight } \\
\text { (g/100 g) }\end{array}$ & $0.231 \pm 0.003$ & $0.227 \pm 0.021$ \\
\hline
\end{tabular}

Values are means \pm SEM calculated from $n=6$ in each group. SMF, exposed rats; $p>0.05$ SMF $v s$. C.

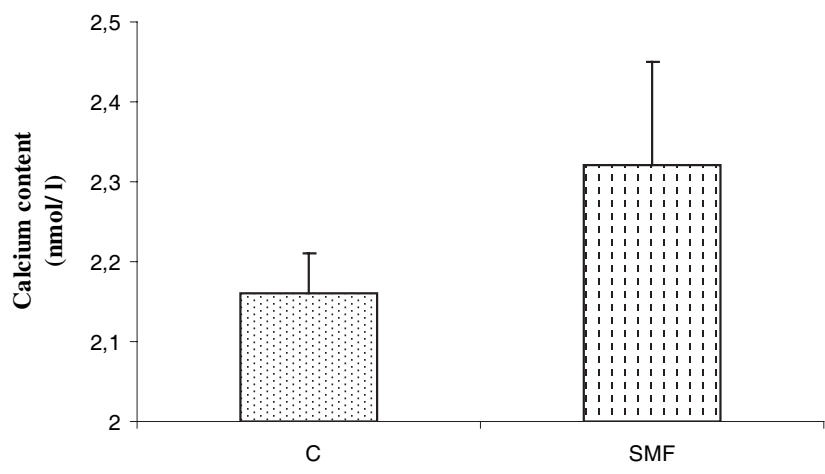

Figure 4. Effect of acute exposure to static magnetic field on plasmatic calcium content. Values are means \pm SEM calculated from $n=6$ in each group. C, sham control; SMF, exposed rats; $p>0.05$ vs. C.

0.05). As shown in Table 1, relative spinal cord weight was unaffected following SMF exposure (0.227 $\pm 0.021 v s .0 .231 \pm$ $0.003 \mathrm{~g} / 100 \mathrm{~g}, p>0.05)$.

\section{Plasma iron and calcium contents}

Iron content was strongly reduced in plasma of SMF exposed rats compared to sham rats $(43.07 \pm 0.91$ vs. $51.4 \pm$ $3.4 \mu \mathrm{mol} / \mathrm{l}, p<0.05$ ) (Figure 3) whereas plasmatic calcium content was unaffected $(2.32 \pm 0.13 v s .2 .161 \pm 0.050 \mathrm{nmol} / \mathrm{l}$, $p>0.05$ ) (Figure 4).

\section{Ionic composition of spinal cord}

As shown in Figure 5, acute exposure to SMF (128 mT) during 1 hour/day for five consecutive days increased the calcium $(3.39 \pm 0.84 v s .2 .09 \pm 0.69 \mathrm{ng} / \mathrm{mg}$ of tissue, $p<0.05)$ and iron $(3.69 \pm 0.53$ vs. $2.73 \pm 0.21 \mathrm{ng} / \mathrm{mg}$ of tissue, $p<0.05)$ contents in rat spinal cord, whereas magnesium $(0.260 \pm 0.033$ vs. $0.153 \pm 0.031 \mathrm{ng} / \mathrm{mg}$ of tissue, $p>0.05)$ and copper content $(4.83 \pm 0.53 v s .4 .47 \pm 0.72 \mathrm{ng} / \mathrm{mg}$ of tissue, $p>0.05$ ) remained unchanged (Figures 6 and 7).

\section{Discussion}

Major elements and trace elements play an important role in human health. Deficiency and excess (toxicity) of these, resulting from exposure to both the natural and man-made environment, can lead to a wide variety of clinical effects (Brown et al. 2004). The monitoring of trace elements status via tissue sampling has important implications for the identification and correction of such effects. In our investigation, acute exposure to SMF induced a decrease iron concentration and failed to alter 


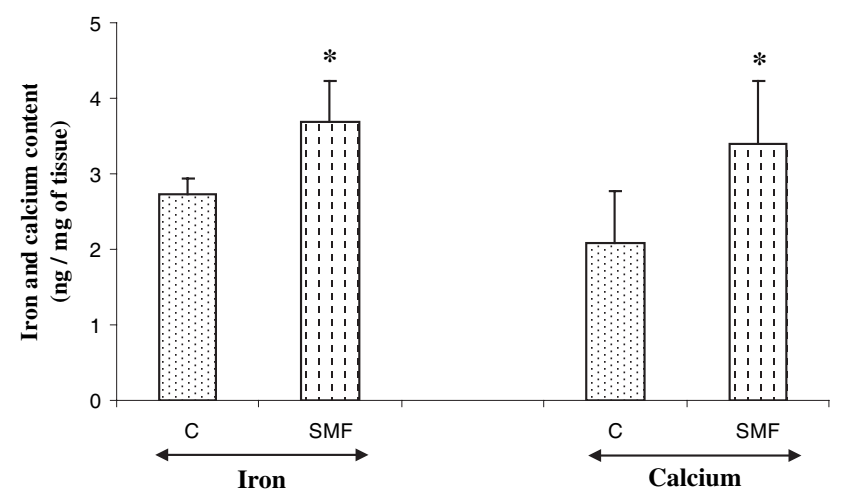

Figure 5. Effect of acute exposure to static magnetic field on iron and calcium contents on rat spinal cord. Values are means \pm SEM calculated from $n=6$ in each group. C, sham control; SMF, exposed rats; ${ }^{*} p<0.05 v s$. C.

calcium level in plasma. However, in spinal cord, the same treatment provided the increase of iron and calcium amounts with no change in magnesium and copper levels. Calcium homoeostasis that results from the interactions of three processes (bone resorption, tubular reabsorption and intestinal absorption) was rapidly reached (Bronner 1973; Parfitt 2003). Therefore, we cannot conclude on the effect of SMF exposure on plasma calcium concentration. The effects of fields on biological systems have yielded compelling data for the involvement of the calcium signalling pathway as the primary target of magnetic fields (Gartzke and Lange, 2002). Recently, Belton et al. (2009) showed that the application of 1, 10, or $100 \mathrm{mT}$ SMF during 800 seconds did not affect the cytosolic free calcium response to ATP in HL-60 cells. Blackman et al. (1985) following the line of research started by Bawin and Adey (1976) found that, in vitro, certain combinations of low frequency and SMF enhance the efflux of calcium ions in chick brain. In the present work, we show that acute exposure to $128 \mathrm{mT}$ SMF ( $1 \mathrm{~h}$ /day for 5 days) decreased the plasmatic iron level. This result is consistent with previous observations indicating a decrease in blood iron in workers exposed to electromagnetic field ( $40 \mu \mathrm{T}, 10$ years) (Nourmohammadi et al. 2001). In the same way, Hachulla (2000) reported that iron decreased in plasma of riverside high line tension. However, in frog sciatic nerve, SMF exposure (67 $\mathrm{mT}, 1 \mathrm{~h}$ /day for 3 consecutive days) increased the calcium and iron contents, while magnesium and copper levels remained constant (Amara et al. 2004). The concentration of copper, manganese, cobalt, and iron in the liver and kidneys of fertilized and not-fertilized rats exposed to static and low-frequency magnetic fields has been analysed. No change in concentration of the above-mentioned metals has been observed in pregnant rats after exposure to static field. However, significant changes have been noticed in fertilized animal exposed 2 hours daily to low-frequency magnetic fields (Duda et al. 1991). In our investigation, reduction of plasma iron could be caused either by decrease iron intestinal absorption or by the leak of iron to other compartments. Indeed, Abdelmelek et al. (2006) demonstrated that SMF induced sympathetic hyperactivity in rats that could influence negatively the intestinal peristaltic activity implicated in the assimilation of divalent elements such as iron. The decrease in plasma iron also may result from the leak of iron to other compartments. In accord with this hypothesis, exposure to SMF increased both iron and calcium level in rat spinal cord. This elevation could be due to the increase of blood-brain barrier permeability (Quock 1987; Finnie 2002). Exposure of rats to a standard clinical MRI procedure temporarily increased the blood-brain barrier permeability to horseradish peroxidase (Prato et al. 1990) and to Evans Blue labeled proteins (Salford et al. 1994). A change of the blood-brain barrier permeability may allow passing in the nerve cells substances such the albumin, ions, chemical substances (Frey 1984; Quock 1987), viruses (Lange and Sedmak 1991), metals

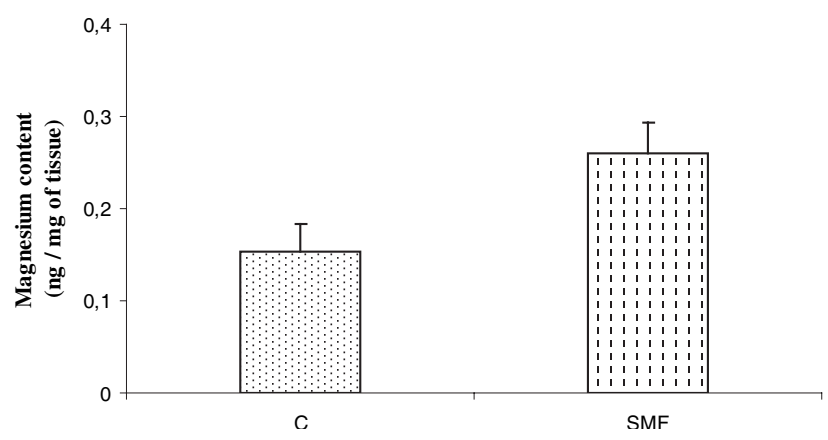

Figure 6. Effect of acute exposure to static magnetic field on magnesium content on rat spinal cord. Values are means \pm SEM calculated from $n=6$ in each group. C, sham control; SMF, exposed rats; $p>0.05 v s$. C.

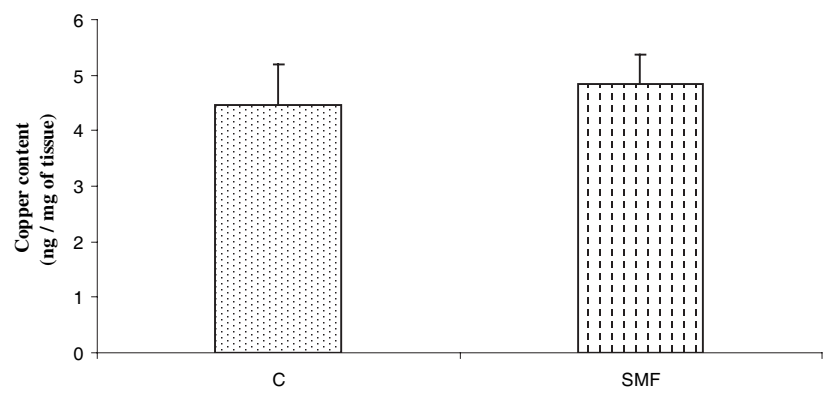

Figure 7. Effect of acute exposure to static magnetic field on copper content on rat spinal cord. Values are means \pm SEM calculated from $n=$ 6 in each group. C, sham control; SMF, exposed rats; $p>0.05 v s$. C. 
and divalent elements (Amara et al. 2004). These changes can lead to functional alterations in the nervous system and the behaviour of animals after SMF exposure, which consequently can increase the risk of Alzheimer's and Parkinson's diseases (Li and Sung 2003).

This study provides evidence that acute SMF exposure may induce important deregulations of ionic composition in CNS that might favor the development of neurodegenerative diseases.

Acknowledgements. This work was supported by the Tunisian Ministry of High Education and Scientific Research.

\section{References}

Abdelmelek H., Chater S., Sakly M. (2001): Acute exposure to magnetic field depresses shivering thermogenesis in rat. Biomedizinische Technik-Band46-Ergiinzungsband 2, 164-166

Abdelmelek H., Chater S., Smirani R., M'Chirgui A., Ben Jeddou C., Ben Salem M., Sakly M. (2000): Effects of $50 \mathrm{~Hz}$ sinusoidal waveform magnetic field on dehydrated rat body. Millennium International Workshop on Biological Effects of Electromagetic fields. pp. 474-479

Abdelmelek H., Molnar A., Servais S., Cottet-Emnard J. M., Pequignot J. M., Favier R., Sakly M. (2006): Skeletal muscle HSP72 and norepinephrine response to static magnetic field in rat. J. Neural. Transm. 7, 821-827; doi:10.1007/s00702-005-0364-7

Amara S., Abdelmelek H., Sakly M. (2004): Effect of acute exposure to magnetic field on ionic composition frog sciatic nerve. Pak. J. Med. Sci. 20, 91-96

Bawin S. M., Adey W. R. (1976): Sensitivity of calcium binding in cerebral tissue to weak environmental electric fields oscillating at low frequency. Proc. Natl. Acad. Sci. 73, 1999-2003; doi:10.1073/pnas.73.6.1999

Belton M., Prato F. S., Rozanski C., Carson J. J. (2009): Effect of 100 $\mathrm{mT}$ homogeneous static magnetic field on $[\mathrm{Ca} 2+] \mathrm{c}$ response to ATP in HL-60 cells following GSH depletion. Bioelectromagnetics 30, 322-329; doi:10.1002/bem.20475

Blackman C. F., Benane S. G., House D. E., Joines W. T. (1985): Effects of ELF $(1-120 \mathrm{~Hz})$ and modulated $(50 \mathrm{~Hz}) \mathrm{RF}$ field on the efflux of calcium ions from brain tissue, in vitro. Bioelectromagnetics 6, 1-11; doi:10.1002/ bem.2250060102

Bronner F. (1973): Calcium homeostasis. In: Engineering Principles in Physiology. (Eds. J. H. U. Brown and D. S. Ganneds), pp. 227-248, New York-London

Brown C. J., Cheneryb S. R. N., Smith B., Mason C., Tomkins A., Roberts G. J., Sserunjogie L., Tiberindwae J. V. (2004): Environmental influences on the trace element content of teeth implications for disease and nutritional status. Arch. Oral. Biol. 49, 705-717; doi:10.1016/j.archoralbio.2004.04.008

Buemi M., Marino D., Di Pasquale G., Floccari F., Senatore M., Aloisu C., Grasso F., Monsio G., Perillo P., Frisina N.,
Corica F. (2001): Cell proliferation/cell death balance in renal cell cultures after exposure to a static magnetic field. Nephron 87, 269-273; doi:10.1159/000045925

Burchard J. F., Nguyen D. H., Block E. (1999): Macro- and trace element concentrations in blood plasma and cerebrospinal fluid of dairy cows exposed to electric and magnetic fields. Bioelectromagnetics 20, 358-364; doi:10.1002/(SICI)1521-186X(199909)20:6<358::AID-BEM4>3.0.CO;2-B

Duda D., Grzesik J., Pawlicki K. (1991): Changes in liver and kidney concentration of copper, manganese, cobalt and iron in rats exposed to static and low-frequency $(50 \mathrm{~Hz})$ magnetic fields. J. Trace Elem. Electrolytes Health Dis. 5, 181-186

Fanelli C., Coppola S., Barone R., Colussi C., Gualandi G., Volpe P., Ghibelli L. (1999): Magnetic fields increase cell survival by inhibiting apoptosis via modulation of $\mathrm{Ca} 2+$ influx. FASEB J. 13, 95-102

Finnie J. W. (2002): Effect of long-term mobile communication microware exposure on vascular permeability in mouse brain. Pathology 7, 334-344

Frey A. H. (1984): Possible modification of the blood-vitreous humor barrier of the eye with electromagnetic energy. J. Bioelectricity 3, 281-292

Gartzke J., Lange K. (2002): Celluar target of weak magnetic fields: ionic conduction along actin filaments of microvilli. Am. J. Physiol. Cell. Physiol. 283, 1333-1346

Hachulla E. (2000): Pseudo-iron deficiency in a French population living near high-voltage transmission lines: a dilemma for clinicians. Eur. J. Intern. Med. 11, 351-352; doi:10.1016/ S0953-6205(00)00114-X

Ichioka S., Iwasaka M., Shibata M., Harii K., Kamiya A., Ueno S. (1998): Biological effects of static magnetic fields on the microcirculatory blood flow in vivo: a preliminary report. Med. Biol. Eng. Comput. 36, 91-95; doi:10.1007/ BF02522863

Lai H., Singh N. P. (2004): Magnetic-field-induced DNA strand breaks in brain cells of the rat. Environ. Health. Perspect. 112, 687-694;

Lange D. G., Sedmak J. (1991): Japanese encephalitis virus (JEV): potentiation of lethality in mice by microwave radiation. Bioelectromagnetics 12, 335-348; doi:10.1002/ bem. 2250120603

Li C. Y., Sung F.C. (2003): Association between occupational exposure to power frequency electromagnetic fields and amyotrophic lateral sclerosis. Am. J. Ind. Med. 43, 212-220; doi:10.1002/ajim.10148

Lin H., Goodman R., Shirly-Henderson A. (1994): Specific region of the c-myc promoter is responsive to electric and magnetic fields. J. Cell. Biochem. 54, 281-288; doi:10.1002/ jcb.240540304

Lopucki M., Czekierdowski A., Rogowska W., Kotarski J. (2004): The effect of oscillating low intensity magnetic field on the $\mathrm{Na}, \mathrm{K}, \mathrm{Ca}$, and $\mathrm{Mg}$ concentrations in the maternal and fetal circulation of the dually perfused human placental cotyledon. Bioelectromagnetics 25, 329-337; doi:10.1002/bem.10201

Nourmohammadi I., Ahmadvand H., Taghikhani M. (2001): Evaluation of levels of macro- and micro-nutrients in 
workers exposed to electromagnetic fields and comparison with levels of patients with leukemia. Iran Biomed. J. 5, 79-85

Parfitt A. M. (2003): Misconceptions (3): Calcium leaves bone only by resorption and enters only by formation. Bone 33, 259-263

Prato F. S., Frappier J. R., Shivers R. R., Kavaliers M., Zabel P., Drost D., Lee T. Y. (1990): Magnetic resonance imaging increases the blood-brain barrier permeability to 153-gadolinium diethylenetriaminepentaacetic acid in rats. Brain Res. 23, 301-304; doi:10.1016/0006 8993(90)91502-8

Quock R. S. (1987): Microwave facilitation of dompridone antagonisme of apomorphisme-induced stereotypic climing in mice. Bioelectromagnetics 8, 45-55; doi:10.1002/ bem. 2250080107

Rosen A. D. (2003): Mechanism of action of moderate-intensity static magnetic fields on biological systems.
Cell. Biochem. Biophys. 39, 163-173; doi:10.1385/ CBB:39:2:163

Roy S., Eckert V., Traber M. G., Mori A., Liburdy R., Paker L. (1995): The phorbol 12-myristate 13-acetate (PMA)-induced oxidative burst in rat peritoneal. FEBS Lett. 37, 164-166; doi:10.1016/0014-5793(95)01266-X

Salford L. G., Brun A., Sturesson K., Eberhardt J. L., Persson B. R. (1994): Permeability of the blood-brain barrier induced by $915 \mathrm{MHz}$ electromagnetic radiation, continuous wave and modulated at $8,16,50$, and $200 \mathrm{~Hz}$. Microsc. Res. Tech. 27, 535-542; doi:10.1002/jemt.1070270608

Suzuki Y., Ikehata M., Nakamura K., Nishioka M., Asanuma K., Koana T., Shimizu H. (2001): Induction of micronuclei, in mice exposed to static magnetic fields. Mutagenesis 16, 499-501; doi:10.1093/mutage/16.6.499

Received: March 9, 2010

Final version accepted: May 9, 2010 